\title{
Fabrication of Organic Thin-Film Transistor Using Soluble Dibenzochrysene
}

\author{
Tatsuo Mori, Keisuke Fujita, and Makoto Kimura* \\ Department of Electrical Engineering and Computer Science, \\ *Department of Applied Physics, Graduate School of Engineering, \\ Nagoya University, Furo-cho, Chikusa, Nagoya, Aichi 464-8603, Japan \\ tmori@nuee.nagoya-u.ac.jp
}

\begin{abstract}
Dibenzo[g,p]chrysene (DBC), which belongs to a cyclic aromatic hydrocarbon similar to pentacene, is drawn attention to. DBC is soluble and dissolves in THF, etc. We estimate the crystal structure of DBC by XRD and the morphology of evaporated and spin-coated DBC thin film by atomic force microscope. $\mathrm{DBC}$ is used as the active layer of organic thin-film transistor (TFT). The TFT characteristics cannot be obtained in a top contact-type TFT structure, but those can be done in a bottom contact-type TFT structure using $\mathrm{SiO}_{2} / \mathrm{Si}$ substrate. Unfortunately, the TFT mobility is $10^{-5} \mathrm{~cm}^{2} /$ Vs-order and poorer than that of pentacene TFT because of broken carrier paths between DBC grains and many discrete valleys.
\end{abstract}

Keywords : dibenzochrysene, organic thin-film transistor, solubility, mobility, FET

\section{Introduction}

Organic thin-film transistors (OTFTs) can be fabricated at low temperature. That is, it is easy to fabricate OTFTs on plastic films with low heat-resistance. The development of OTFTs attracts increasing attention from many researchers. Recently we are amazed at the rapidity of advance on OTFT characteristics. The carrier mobilities of OTFT using organic single crystal are reported to be beyond $10 \mathrm{~cm}^{2} / \mathrm{Vs}[1-4]$. These values are higher than that of amorphous silicone TFT. One is interested in OTFTs using organic single crystals in the viewpoint of physics. However, organic single crystals are not handled easily because of small size and friability. It is important to develop OTFTs which solve the disadvantages of inorganic TFTs. The advantage that OTFTs can be fabricated by low-temperature $\left(<200{ }^{\circ} \mathrm{C}\right)$ process, i.e. spin-coating and printing, is given as an example. The mobilities of OTFTs using pentacene which have been used as an active layer are reported to be at most $1 \mathrm{~cm}^{2} / \mathrm{Vs}[5-7]$. However, it is demonstrated that OTFTs with these mobilities can drive liquid crystal and organic light-emitting diode displays[8-15]. The disadvantages are that pentacene films cannot be fabricated by a solution process because of insolubility, that it takes a long time to fabricate evaporated pentacen films with large grains because of a very deposition rate, and that pentacene is unstable in air because of a narrow HOMO-LUMO gap. Therefore, many soluble and stable materials are developed and reported: for example, TIPS-pentacene[16,17], Cn-BTBTs[18], thiophene oligomers[19], etc[20-26].

We pay attention to dibenzochrisene (DBC). $\mathrm{DBC}$ is a cyclic aromatic hydrocarbon similar to pentacene, but is soluble. In this paper, we fabricate DBC films by evaporation and spin-coating methods and study the morphology and film characteristics of DBC films. In addition, we use DBC as an active layer of OTFT for the first time and measure the TFT characteristics of DBC TFT as compared with pentacene.

\section{Experimental}

Dibenzo[g,p]chrysene (DBC) and pentacene as a reference was obtained from Kurogane Kasei Co.Ltd. Glass substrates were rinsed by supersonic cleaning of water and organic solvents. After UV-ozone cleaning, $\mathrm{Cr} / \mathrm{Au}$ was evaporated as a gate electrode on a glass substrate. Polyimide thin film was fabricated by spin-coating and post-annealing. Organic semiconductors were 
fabricated by a vacuum-deposition method. DBC thin films were also spin-coated on polyimide insulating layer. Finally, $\mathrm{Au}$ was evaporated as source and drain electrodes on an organic semiconductor layer. The length and width of channel between source and drain electrodes were $-50 \mu \mathrm{m}$ and $\sim 2 \mathrm{~mm}$, respectively. We also used the bottom contact-type, $\mathrm{SiO}_{2} / \mathrm{Si}$ substrate purchased from Q-Lights. In this case, the length and width of channel between source and drain electrodes were 30 or $50 \mu \mathrm{m}$ and $\sim 2 \mathrm{~mm}$, respectively. We measured absorption spectra using a spectrophotometer (U-3000; Hitachi Ltd.), ionization potential (Ip) using photoelectron spectroscopy in air (AC-2; Riken Keiki Co. Ltd.), and surface morphology using an atomic force microscope (VN-8000; Keyence Co.). The single crystal analysis of DBC was carried out using microfocus X-ray generators. VariMax optical systems (Rigaku Co.). The TFT characteristics were measured using a source measurement unit (2400 Source Meter; Keithley Instruments, Inc.) in micro vacuum chamber (MJ-8S, Measure Jig Co.Ltd.).

\section{Results and Discussions}

\subsection{Properties and crystal of DBC}

DBC dissolves in THF by $>11 \mathrm{wt} \%(>0.32$ $\mathrm{mol} / \mathrm{l})$, in chloroform by $6 \mathrm{wt} \%(0.17 \mathrm{~mol} / \mathrm{l})$, and in acetone by $0.35 \mathrm{wt} \%(0.01 \mathrm{~mol} / \mathrm{l})$.

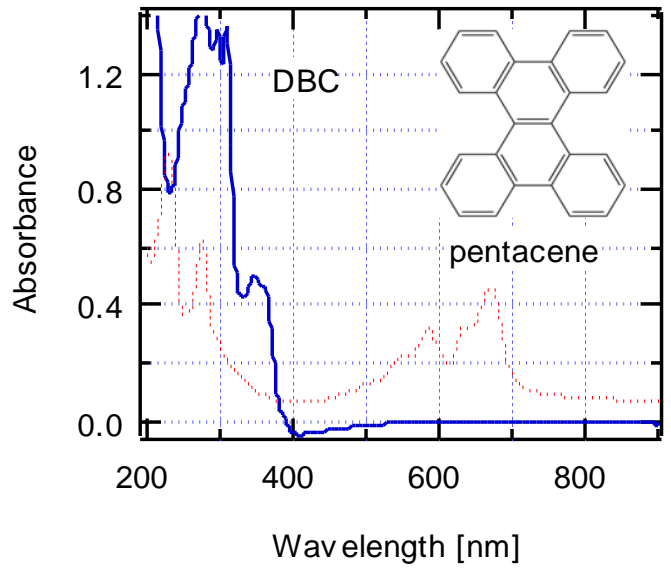

Fig. 1 The absorbance of evaporated DBC and pentacene thin films (thickness, $100 \mathrm{~nm}$ ) with DBC chemical structure.

Fig. 1 shows the absorbance of evaporated DBC and pentacene thin films (thickness, $100 \mathrm{~nm}$ ). DBC does not have the absorption in the wavelength region of 400-900 $\mathrm{nm}$. The threshold of absorption of DBC and pentacene are estimated to be $400 \mathrm{~nm}$ and $710 \mathrm{~nm}$, respectively. Therefore, the optical energy gaps of DBC and pentacene are calculated to be $3.1 \mathrm{eV}$ and $1.8 \mathrm{eV}$, respectively. The ionization potentials of $\mathrm{DBC}$ and pentacene are estimated to be $5.9 \mathrm{eV}$ and $5.0 \mathrm{eV}$, respectively. From these results, DBC is thought to be chemically more stable than pentacene in air.

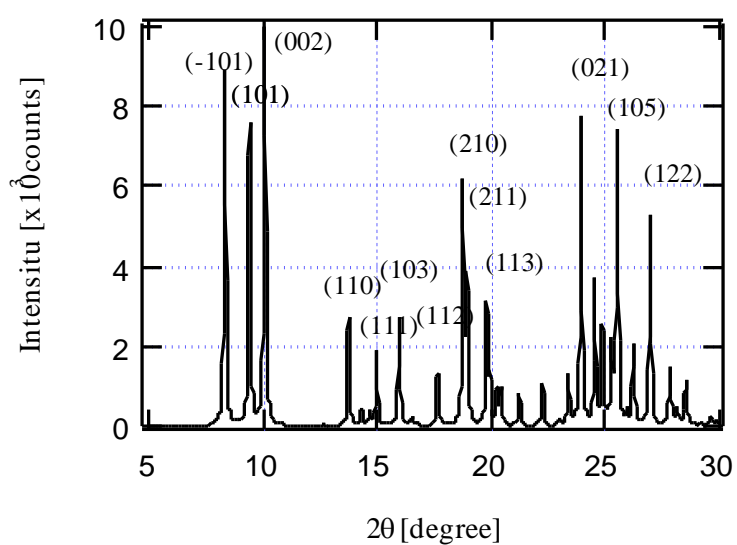

Fig. 2 The XRD pattern of DBC single crystal

Fig. 2 shows the XRD pattern of $\mathrm{DBC}$ single crystal. The crystal structure of DBC is a monoclinic crystal. The crystal index of $\mathrm{DBC}$ crystal is $a=12.16 \AA, b=7.60 \AA, c=17.67 \AA, \alpha=90^{\circ}$, $\beta=97.43^{\circ}$, and $\gamma=90^{\circ}$. Fig. 3 shows the molecular alignment in the DBC crystal. We use the follow after calculating crystal indexes.

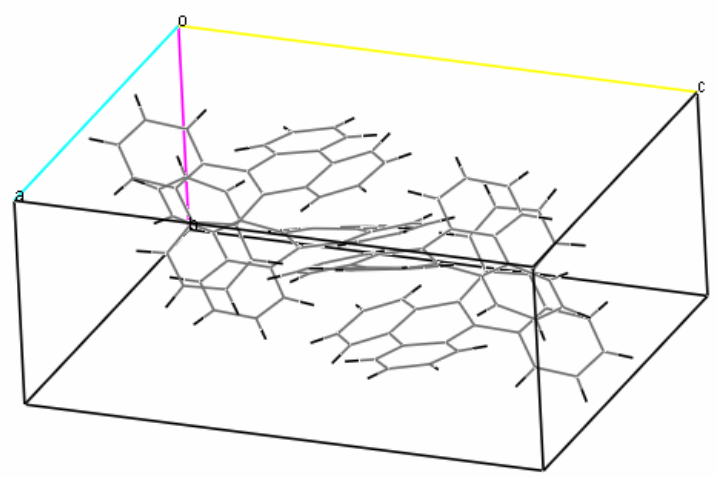

Fig. 3 The molecular alignment in the DBC crystal

\subsection{Morphology and structures of DBC}

Fig. 4 shows the AFM image of pentacene film $(60 \mathrm{~nm})$ on polyimide insulating film. The deposition rate is $0.0023 \mathrm{~nm} / \mathrm{s}$ and the substrate temperature is $80{ }^{\circ} \mathrm{C}$. The grain size is $2-3 \mu \mathrm{m}$. On the other hand, Figs. 5a and 5b show the AFM images of DBC-evaporated films on glass immediately after deposition. The deposition rates are $0.2 \mathrm{~nm} / \mathrm{s}$ (5a) and $0.002 \mathrm{~nm} / \mathrm{s}$ (5b). The roughness of DBC thin film evaporated by the deposition rate of $0.2 \mathrm{~nm} / \mathrm{s}$ is smooth. In the DBC 
film evaporated by the deposition rate of 0.002 $\mathrm{nm} / \mathrm{s}$, grains of $1 \mu \mathrm{m}$-width and $2 \sim 4 \mu \mathrm{m}$-height are observed. These morphologies are not stable.

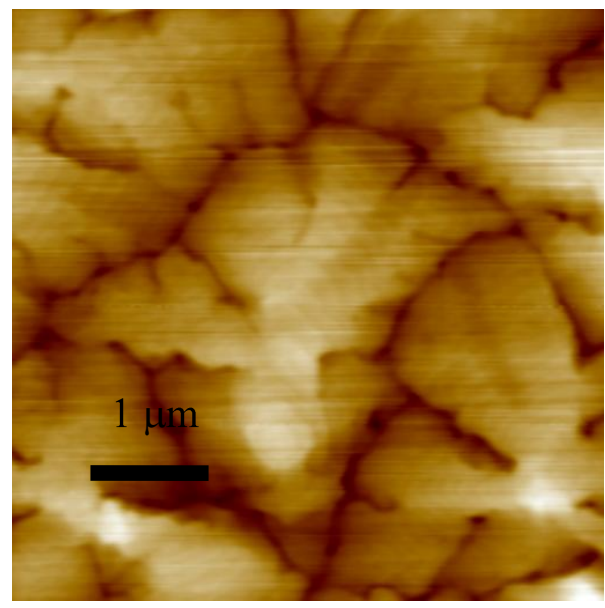

$40 \mathrm{~nm}$

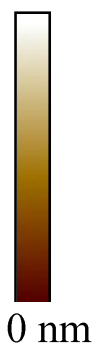

Fig. 4 The AFM image of pentacene film $(60 \mathrm{~nm})$ on polyimide insulating film
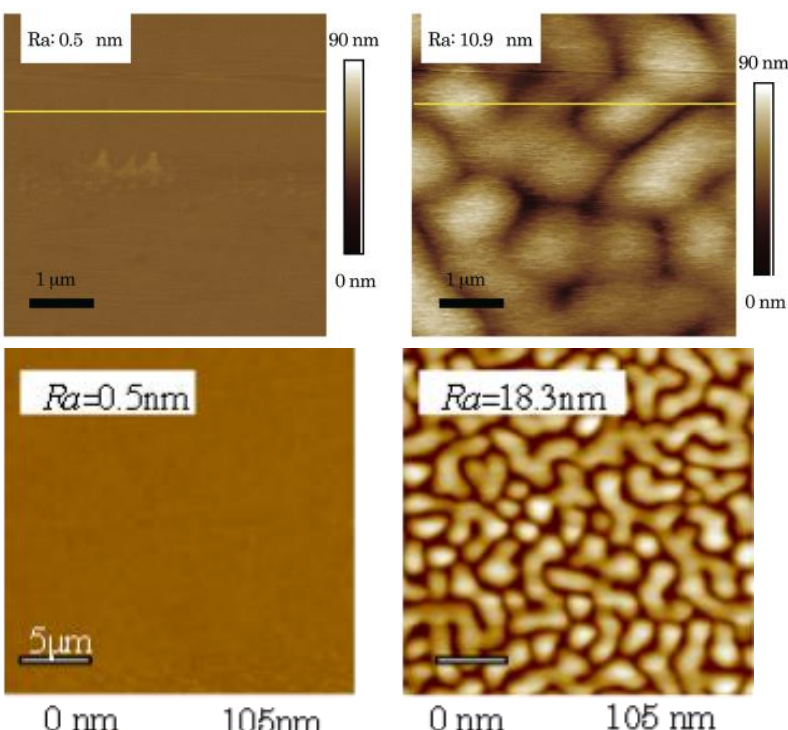

$0 \mathrm{~nm} \quad 105 \mathrm{~nm}$

(a) $0.2 \mathrm{~nm} / \mathrm{s}$
However, the holes of $>1 \mu \mathrm{m}$-diameter and 150 nm-depth are also observed especially in Fig. 6 b. The holes penetrate from the surface to glass substrate. The change of film morphology is thought to be due to molecular migration. The as-grown DBC thin films are thought to be amorphous. After molecular migration for some days, the DBC thin films will be polycrystallized.

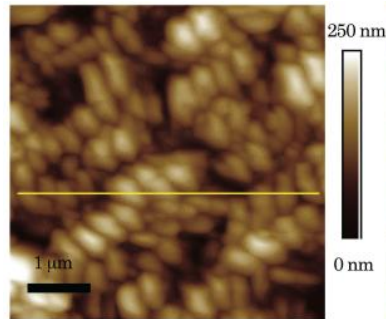

(a) $0.2 \mathrm{~nm} / \mathrm{s}$

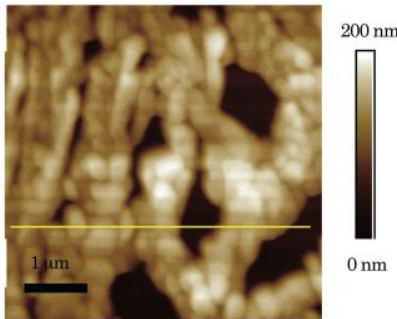

(b) $0.002 \mathrm{~nm} / \mathrm{s}$
Fig. 6 The AFM image of DBC- evaporated film $(100 \mathrm{~nm})$ on glass after 3 days: (a) $0.2 \mathrm{~nm} / \mathrm{s}$, (b) $0.002 \mathrm{~nm} / \mathrm{s}$.

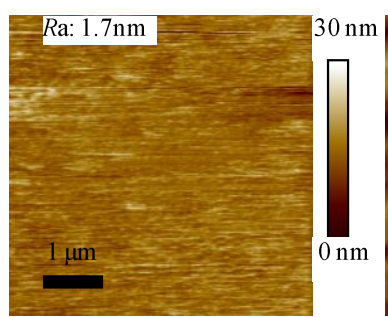

(a) as-coated

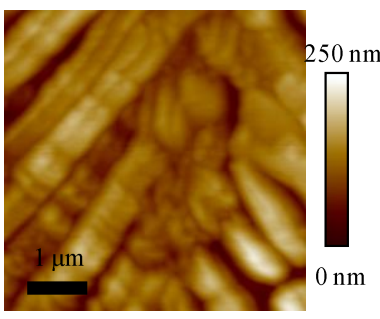

(b) after anneal
Fig. 7 The AFM image of DBC-spin-coated film $(100 \mathrm{~nm})$ on glass: (a) as-coated, (b) after anneal.

Fig. $7 \mathrm{a}$ and $7 \mathrm{~b}$ show the AFM images of DBC-spin-coated films on glass immediately after coat and annealing. The spin-coating conditions are THF solution ( $0.05 \mathrm{~mol} / \mathrm{l})$ and $2000 \mathrm{rpm}$. The thickness is $100 \mathrm{~nm}$ under the conditions. The anneal conditions are $100{ }^{\circ} \mathrm{C}$ for 3 hours under $\mathrm{N}_{2}$ flow. The roughness of as-grown DBC-spin-coated film is smooth. On the other hand, although the small grains as well as the evaporated DBC film after 3 days are observed, these small grains form some band-like domains. The annealed DBC film morphology is the aggregation of small grains and includes many discrete valleys. This morphology can be observed in annealed DBC-evaporated thin films. It is thought not to be suitable for TFT.

Figs. 8a and 8b show the XRD patterns of as-grown and annealed DBC-evaporated films and as-coated and annealed DBC-spin-coated films, respectively. Any peak are not observed in XRD patterns of as-grown DBC-evaporated and 
-spin-coated films. Therefore, as-grown DBC-evaporated and -spin-coated films are amorphous, although DBC forms large domains similar to pentacene.

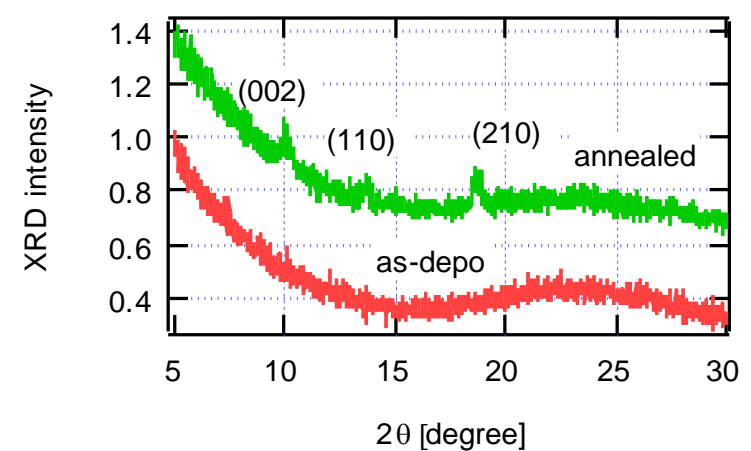

(a) evaporated DBC films

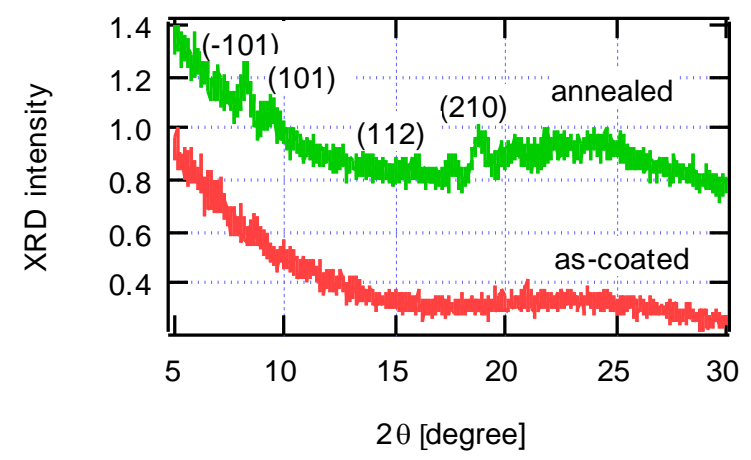

(b) spin-coated DBC films

Fig. 8 The XRD patterns of DBC films $(100 \mathrm{~nm})$ on glass: (a) as-coated, (b) after anneal.

The anneal treatment accelerates the polycrystallization of DBC molecules. The crystallization behavior of DBC-evaporated films is different from that of DBC-spin-coated films after annealing. The peak of (210) is observed in both annealed specimens. The peaks of (002) and (110) are observed in the annealed DBC-evaporated film and the peaks of (-101), (101) and (112) are done in the annealed DBC-spin-coated film.

\subsection{TFT characteristics of DBC}

Fig. 9 shows the typical output characteristics of pentacene TFT fabricated as a reference. The TFT mobility and on/off ratio of our pentacen TFT are $0.5 \mathrm{~cm}^{2} / \mathrm{Vs}$ and $10^{6}$, respectively. These values are popular as compared with the others[5,6]. It is found that there is no problem in our TFT measurement system.

Fig. 10 shows the output characteristics of DBC TFT fabricated by spin-coating method. Drain currents do not flow even if gate voltage increases up to $90 \mathrm{~V}$. We cannot obtain TFT characteristics for DBC-evaporated TFT, too. Fig. 11 shows the
AFM image of DBC film fabricated between drain and source channels. The deep valleys between grains are observed in DBC films. Therefore, we conclude that the carrier paths are broken in DBC thin films. Consequently, carriers can little be transported between two electrodes.

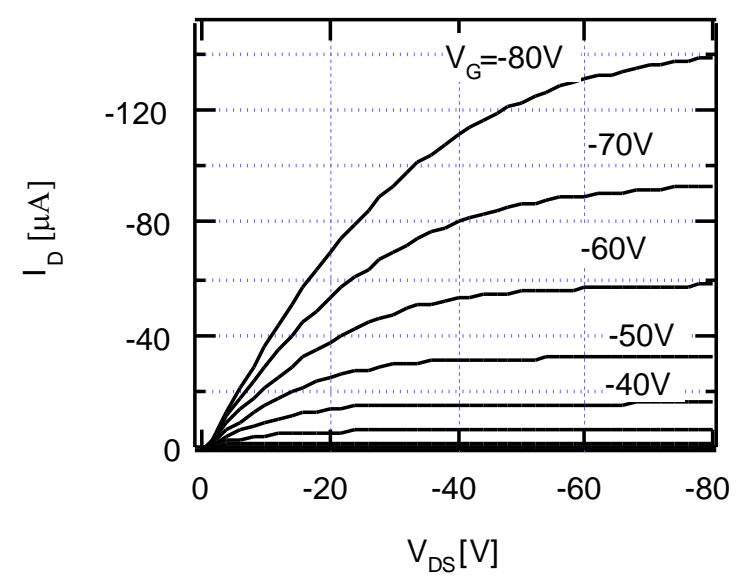

Fig. 9 The output characteristics of top-contact type TFT using evaporated pentacene.

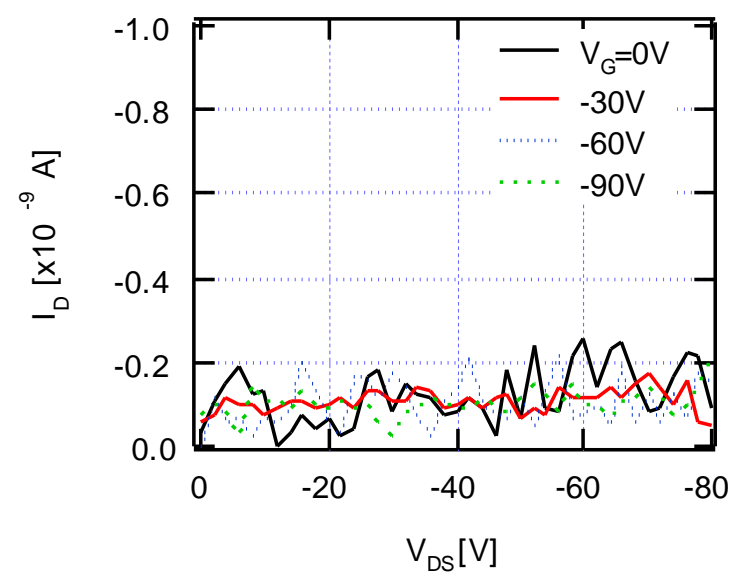

Fig. 10 The output characteristics of top-contact type TFT using spin-coated DBC.

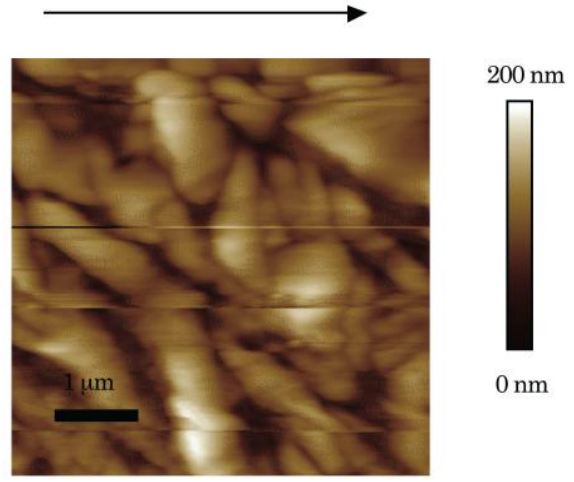

Fig. 11 The AFM image of DBC film in channel.

We think that our top-contact-type TFT structure using polyimide insulating layer may be unsatisfied with TFT measurement in a low-current region. We try to use bottom-contact-type TFT structure using 
$\mathrm{SiO}_{2}$ insulating layer $(400 \mathrm{~nm})$ and $\mathrm{p}^{++} \mathrm{Si}$ gate electrode/substrate. First, we estimate the TFT characteristics of pentacene-evaporated film. The TFT mobility and on/off ratio of our pentacen TFT are $0.05 \mathrm{~cm}^{2} / \mathrm{Vs}$ and $10^{5}$, respectively. These values are poorer than those of top-contact-type TFT. This is thought to be due to hydroxyl group on $\mathrm{SiO}_{2}[27,28]$.

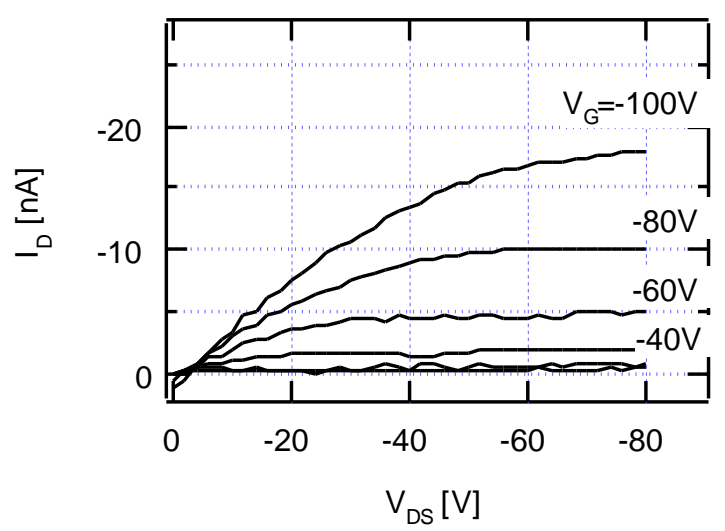

(a) Output characteristics of as-depo. DBC TFT

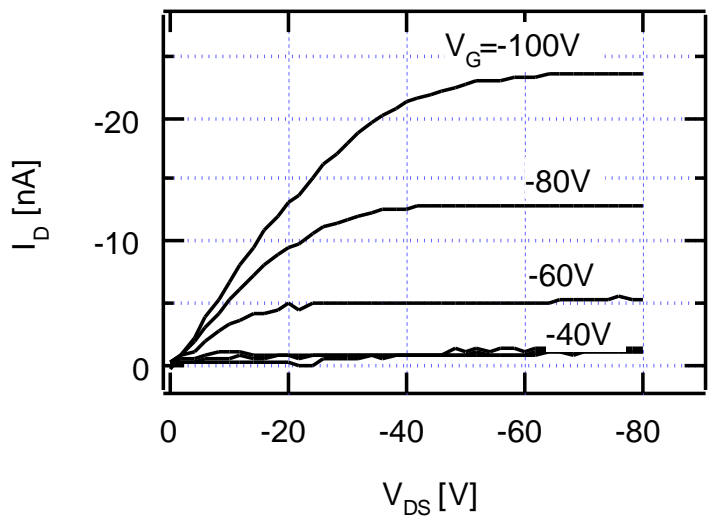

(b) Output characteristics of annealed DBC TFT

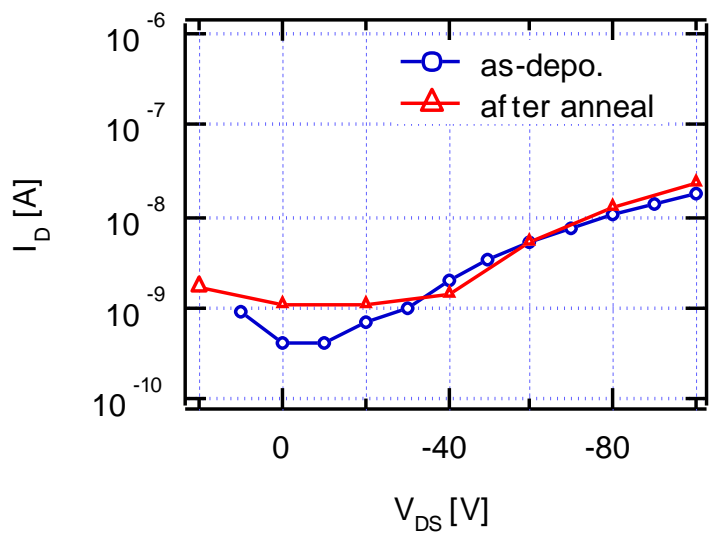

(c) Transfer characteristics of the above DBC TFTs

Fig. 12 The TFT characteristics of as-depo. and annealed DBC TFTs.

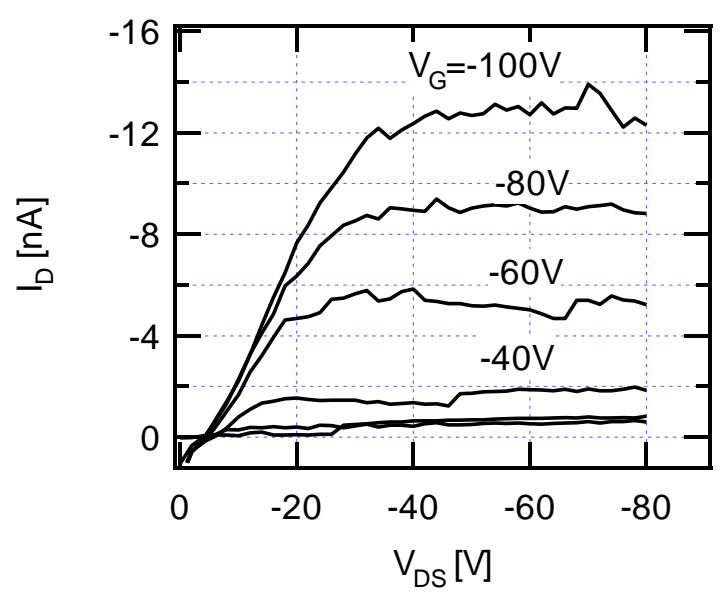

Fig. 13 The TFT characteristics of annealed DBC-spin-coated TFTs.

Figs. 12 show the output and transfer characteristics of DBC TFTs using evaporated layer. Although drain currents are very low, TFT characteristics can be measured even in an amorphous DBC film. The TFT mobility and on/off ratio of amorphous DBC TFT are $2 \times 10^{-5} \mathrm{~cm}^{2} / \mathrm{Vs}$ and $<10^{2}$, respectively. Anneal treatment slightly improves TFT mobility. The TFT mobility and on/off ratio of annealed DBC TFT are $2.5 \times 10^{-5}$ $\mathrm{cm}^{2} / \mathrm{Vs}$ and $<10^{2}$, respectively. Fig. 13 shows the output characteristics of DBC TFTs using spin-coated layer. The TFT characteristics of as-spin-coated DBC layer cannot be measured but those of annealed spin-coated DBC layer can be done. The TFT mobility and on/off ratio of annealed DBC TFT are $1.5 \times 10^{-5} \mathrm{~cm}^{2} / \mathrm{Vs}$ and $<10^{2}$, respectively. We speculate that the low TFT mobility of DBC TFT is caused from AFM images by broken carrier paths in DBC grains. Table 1 shows summary of TFT characteristics in this paper.

Table 1 Summarized TFT characteristics. A. top contact $(\mathrm{Au}(\mathrm{G})$-PI-organic $-\mathrm{Au}(\mathrm{S}-\mathrm{D}))$

\begin{tabular}{|c|c|c|c|c|}
\hline material & & $\begin{array}{c}\mu_{\mathrm{h}} \\
{\left[\mathrm{cm}^{2} / \mathrm{Vs}\right]}\end{array}$ & $\begin{array}{c}\text { on/off } \\
\text { ratio }\end{array}$ & $\begin{array}{l}V_{\text {th }} \\
{[\mathrm{V}]}\end{array}$ \\
\hline pentacene & annealed & 0.27 & $10^{5}$ & -18 \\
\hline \multicolumn{5}{|c|}{ B. bottom contact $\left(\mathrm{Si}(\mathrm{G})-\mathrm{SiO}_{2}-\mathrm{Au}(\mathrm{S}-\mathrm{D})\right.$-organic) } \\
\hline \multicolumn{2}{|l|}{ material } & $\begin{array}{c}\mu_{\mathrm{h}} \\
{\left[\mathrm{cm}^{2} / \mathrm{Vs}\right]}\end{array}$ & $\begin{array}{c}\text { on/off } \\
\text { ratio }\end{array}$ & $\begin{array}{l}V_{\text {th }} \\
{[\mathrm{V}]}\end{array}$ \\
\hline pentacene & as-depo & 0.05 & $10^{5}$ & -8 \\
\hline \multirow{2}{*}{$\begin{array}{l}\text { DBC } \\
\text { (eva.) }\end{array}$} & as-depo & $2 \times 10^{-5}$ & $10^{2}$ & -8 \\
\hline & annealed & $2.5 \times 10^{-5}$ & $<10^{2}$ & -23 \\
\hline \multirow{2}{*}{$\begin{array}{l}\text { DBC } \\
\text { (SC) }\end{array}$} & as-coated & - & - & - \\
\hline & annealed & $1.5 \times 10^{-5}$ & $<10^{2}$ & -1 ? \\
\hline
\end{tabular}




\section{Conclusions}

We fabricated the top-contact-type TFT structure using polyimide insulating layer and the bottom-contact-type TFT structure using $\mathrm{SiO}_{2}$ insulating layer and $\mathrm{p}^{++} \mathrm{Si}$ gate electrode/substrate, using pentacene and $\mathrm{DBC}$ thin films as an active layer. DBC is soluble and a spin-coated DBC layer can be fabricated. We succeeded the fabrication of DBC TFT. Unfortunately, the TFT mobility was low and $\sim 2 \times 10^{-5} \mathrm{~cm}^{2} /$ Vs. Because the annealed DBC film morphology was the aggregation of small grains and included many discrete valleys.

\section{References}

1. E. Menard, V. Podzorov, S. H. Hur, A. Gaur, M.E. Gershenson, J.A. Rogers, Adv. Mater. 16 (2004) 2097.

2. V. Podzorov, E. Menard, A. Borissov, V.

Kiryukhin, J. A. Rogers, M. E. Gershenson, Phys. Rev. Lett., 93 (2004) 086602.

3. J. Takeya, M. Yamagishi, Y. Tominari, R. HIrahara, Y. Nakazawa, T.Nishikawa, T. Kawase, T. Shimoda, S. Ogawa, Appl. Phys. Lett., 90 (2007) 102120.

4. O. D. Jurchescu, J. Baas, T. T. M. Palstra, Appl.

Phys. Lett., 84 (2004) 3061.

5. Y. Lin, D. J. Gundlach, S. F. Nelson, T. N. Jacksom, IEEE Electron Device Lett., 18 (1997) 606.

6. T. Sekitani, S. Iba, Y. Kato, and T. Someya, Appl. Phys. Lett., 85 (2004) 3902.

7. S. Pyo, H. Son, K. Y. Choi, M. H. Yi, S. K. Hong, Appl. Phys. Lett., 86 (2005) 133508.

8. T. Chuman, S. Ohta, S. Miyaguchi, H. Satoh, T. Tanabe, Y. Okuda, M. Tsuchida, SID '04 DIGEST 5.1 (2004) 45.

9. M. Mizukami, N. Hirohata, T. Iseki, K. Ohtawara, T. Tada, S. Yagyu, T. Abe, T. Suzuki, Y. Fujisaki, Y. Inoue, S. Tokito, T. Kurita, IEEE Electron Device Lett. 27 (2006) 249.

10. YW. Choi, S.-S. Yoon, JH Choi, H. J. Kim, J. H. Son, SY. Kim, Y. H. Lee, Y. H. Choi, S. Ta.Kim, II-D. Kim, MW. Lim, SID'06 DIGEST 10.2 (2006) 112.

11.Y. Fujisaki, H. Sato, T. Yamamoto, H. Fujikake, S. Tokito and T. Kurita, J. Soc. for Inform. Display, 15 (2007) 501.

12. M. Kawasaki, S. Imazeki, S. Hirota, T. Arai, T. Shiba, M. Ando, Y. Natsume, T. Minakata, S. Uemura, T. Kamata, SID '07 DIGEST 63.4L (2007) 1761.
13. I. Yagi, N. Hirai, M. Noda, A. Imaoka, Y. Miyamoto, N. Yoneya, K. Nomoto, J. Kasahara, A. Yumoto, T. Urabe, SID '07 DIGEST 63.2 (2007) 1753.

14. S. Tokito, ECS Trans. 16 (2008) 23.

15. Y. Nakajima, T. Takei, T. Tsuzuki, M. Suzuki, H. Fukagawa, T. Yamamoto, and S. Tokito, J. Soc. for Inform. Display, 17/8, (2009) 629.

16. O. D. Jurchescu, S. Subramanian§, R. J. Kline, S. D. Hudson, J. E. Anthony, T. N. Jackson, D. J. Gundlach, Chem. Mater, 20 (2008) 6733

17. D. J. Gundlach, J. E. Royer, S. K. Park, S. Subramanian, O. D. Jurchescu, B. H. Hamadani, A. J. Moad, R. J. Kline, L. C. Teague, O. Kirillov, C. A. Richter, J. G. Kushmerick, L. J. Richter, S. R. Parkin, T. N. Jackson, J. E. Anthony, Nature Mater., 7 (2008) 216.

18. T. Izawa, E. Miyazaki, K. Takimiya, $A d v$. Mater., 20 (2008) 3388.

19. A. Zen, P. Pingle, D. Neher, U. Scherf, phys. stat. sol. (a), 205 (2008) 440.

20. T. D. Anthopoulos, G. C. Anyfantis, G. C. Papavassiliou, D. M. de Leeuw, Appl. Phys. Lett., 90 (2007) 122105.

21. K. Takimiya, Y. Kunugi, T. Otsubo, Chem. Lett., 36 (2007) 578.

22. S. Kinoshita, T. Sakanoue, M. Yahiro, K. Takimiya, H. Ebata, M. Ikeda, H. Kuwabara, C. Adachi, Solid State Commun., 145 ( 2008) 114.

23. T. Sakanoue, M. Yahiro, C. Adachi, K. Takimiya, A. Toshimitsu, J. Appl. Phys., 103, (2008) 094509

24. P. H. Wöbkenberg, D. D.C. Bradley, D. Kronholm, J. C. Hummelen, D. M. de Leeuw, M. Cölle, Thomas D. Anthopoulos, Synth. Met., 158 (2008) 468.

25. T. Izawa, E. Miyazaki, K. Takimiya, Chem. Mater., 21 (2009) 903.

26. U. Zschieschang, F. Ante, T. Yamamoto, K. Takimiya, H. Kuwabara, M. Ikeda, T. Sekitani, T. Someya, K. Kern, H. Klauk, Adv. Mater., 22 (2010) 982.

27. S. Kobayashi, T. Nishikawa, T. Takenobu, S. Mori, T. Shimoda, T. Mitani, S. Shimotani, N. Yoshimoto, S. Ogawa, Y. Iwase, Nat. Mater, 3 (2004) 317.

28. M. Halik, H. Klauk, U. Zschieschang, G. Schmid, C. Dehm, M. Schütz, S. Maisch, F. Effenberger, M. Brunnbauer, F. Stellacci, Nature, 431 (2004) 963. 